\title{
Did Fine Particulate Matter from the Summer 2016 Landscape Fires in Tasmania Increase Emergency Ambulance Dispatches? A Case Crossover Analysis
}

\author{
Laura J. Edwards ${ }^{1,2,3, *(\mathbb{D})}$, Grant Williamson ${ }^{4}$ (D), Stephanie A. Williams ${ }^{2}$, Mark G. K. Veitch ${ }^{1}$, \\ Farhad Salimi ${ }^{3,5,6}$ and Fay H. Johnston 1,3 (1) \\ 1 Population Health Services, Department of Health, Hobart, TAS 7000, Australia; \\ mark.veitch@health.tas.gov.au (M.G.K.V.); fay.johnston@utas.edu.au (F.H.J.) \\ 2 National Centre for Epidemiology and Population Health, Australian National University, \\ Canberra, ACT 2601, Australia; Stephanie.Williams@anu.edu.au \\ 3 Menzies Institute for Medical Research, University of Tasmania, Hobart, TAS 7000, Australia; \\ farhad.salimi@sydney.edu.au \\ 4 School of Natural Sciences, University of Tasmania, Hobart, TAS 7000, Australia; \\ grant.williamson@utas.edu.au \\ 5 University Centre for Rural Health-North Coast, University of Sydney, Sydney, NSW 2000, Australia \\ 6 Centre for Air pollution, Energy and Health Research and Evaluation, Glebe, NSW 2037, Australia \\ * Correspondence: laura.edwards@health.tas.gov.au; Tel.: +61-3-6166-0672
}

Received: 29 May 2018; Accepted: 13 July 2018; Published: 24 July 2018

\begin{abstract}
During summer in early 2016, over 70 landscape fires in Tasmania (Australia) caused several severe episodes of fire smoke across the island state. To assess the health impact of the fire smoke, a case crossover analysis was performed, which measured the association between increased concentrations of $\mathrm{PM}_{2.5}$ and emergency ambulance dispatches (EAD) from 1 January to 31 March 2016. Control days were matched by latitude and longitude, day of the week and calendar month. Exposure data were obtained from air quality monitoring stations at lag times of $1-48 \mathrm{~h}$ and for the 24-h mean on the same day and 1-day lag. Positive associations were observed between an increase of $10 \mu \mathrm{g} / \mathrm{m}^{3}$ in $\mathrm{PM}_{2.5}$ and EAD for stroke on the same day (OR 1.10, 95\% CI 1.02-1.19) and at 1-day lag (OR 1.10, 95\% CI 1.02-1.18). Furthermore, there were non-significant increases in breathing problems (OR 1.04, 95\% CI 1.00-1.08) and diabetic problems (OR 1.11, 95\% CI 0.99-1.22) at 1-day lag. The EAD for all causes were not increased. These findings will be used for ambulance service planning and public health risk communication in future landscape fire events.
\end{abstract}

Keywords: particulate matter; landscape fire smoke; emergency ambulance dispatches

\section{Introduction}

During an unusually hot and dry summer in early 2016, over 70 landscape fires within a 60-day period in Tasmania (Australia) caused severe episodes of fire smoke across the island state. The concentrations of fine particulate matter (microscopic particles with diameters of less than 2.5 micrometers that are suspended in the air; $\mathrm{PM}_{2.5}$ ) were recorded to have an average of up to $500 \mu \mathrm{g} / \mathrm{m}^{3}$ over $24 \mathrm{~h}$, which are far higher than the Australian National Environment Protection Measure (NEPM) Standard of an average 24-h concentration of $25 \mu \mathrm{g} / \mathrm{m}^{3}$. Given the emerging evidence for acute health effects of landscape fire smoke exposure [1], the aim of this study was to investigate if smoke from the Tasmanian landscape fires caused an increase in acute health events.

The health effects of air pollution are predominately due to $\mathrm{PM}_{2.5}$ generated during combustion. These include acute effects, such as asthma exacerbations, myocardial infarction and stroke; and chronic 
effects, such as chronic obstructive pulmonary disease (COPD) and lung cancer. Globally, ambient air pollution is the leading environmental cause of death, resulting in 4.2 million deaths each year (7.6\% of all deaths) [2]. The major global causes of death that are attributable to ambient air pollution include COPD (27.1\%), lung cancer (16.5\%), ischemic heart disease (17.1\%) and cerebrovascular disease (14.2\%) [2]. Among the global burden of disease from ambient air pollution, 340,000 deaths each year have been attributed directly to landscape fire smoke [3].

The previous studies in the setting of landscape fire smoke exposure have shown an increase in acute respiratory conditions [4,5], cardiac arrest [6], cardiovascular mortality [1], non-traumatic emergency department attendances [7] and all-cause mortality [1,8,9], with the elderly and people with pre-existing health conditions being most at risk [5].

Few epidemiological studies have assessed the health effects of air pollution in Australia. One study in Sydney, the largest city in Australia, attributed 2.1\% of all deaths to $\mathrm{PM}_{2.5}$ and ozone exposure [10]. The Global Burden of Disease Study estimated that ambient air pollution causes 12.7 deaths per 100,000 per year in Australia, including 5.8\% of deaths due to COPD, $5.6 \%$ of deaths from ischemic heart disease, $3.8 \%$ of stroke deaths, $4.4 \%$ of lower respiratory infection deaths and $2.5 \%$ of lung cancer deaths [11]. Acute health conditions are often recorded in hospital or emergency department settings. However, these data are limited to the location at which the patient is treated and do not provide information on the exposure of cases to $\mathrm{PM}_{2.5}$.

Emergency ambulance dispatches (EAD) provide information on acute health events and offer an advantage in the studies of environmental exposures by providing geospatial information for cases. The studies of fire smoke exposure and EAD have shown an increase in cardiovascular events, including out-of-hospital cardiac arrest [6,12-14] and chest pain [15]; respiratory problems [16,17]; diabetic symptoms [18]; syncope/fainting [18] and all non-traumatic causes combined [19,20].

The aim of this study was to determine if the increased concentrations of $\mathrm{PM}_{2.5}$ from fire smoke in Tasmania from 1 January to 31 March 2016 were associated with an increase in all-cause, respiratory-related or cardiovascular-related EAD.

\section{Materials and Methods}

\subsection{Setting}

Tasmania is an island state in Southern Australia with a land mass of $68,000 \mathrm{~km}^{2}$ and an estimated resident population of 518,000 in 2016. Tasmania has low concentrations of air pollution during summer with occasional peaks during landscape fires. The NEPM standards are exceeded periodically during winter months in the towns situated in plateaus or valleys due to domestic woodfire emissions. Very little air pollution is generated from industrial sources or traffic [21].

\subsection{Study Design}

A time-stratified case crossover design was used to measure the association between exposure to $\mathrm{PM}_{2.5}$ and EAD. The case crossover design is used in environmental epidemiology to measure the effect of short-term environmental exposures on acute health conditions [22]. In this methodology, the cases also act as their own control. The cases included all individuals who required an EAD during the study period of 1 January to 31 March 2016. The cases were matched to controls according to the day of the week within the same calendar month, which resulted in three or four controls per case.

\subsection{Exposure Data}

Air pollution data were obtained from the Base Line Air Network of EPA Tasmania (BLANKeT), which is a network of 29 stations established to measure $\mathrm{PM}_{2.5}$, along with meteorological variables obtained in the major cities and towns of Tasmania (Figure 1). BLANKeT data provides a good estimate of the population exposure to $\mathrm{PM}_{2.5}$ with $95 \%$ of the Tasmanian population residing within $20 \mathrm{~km}$ of a station [15]. Hourly exposure data of $\mathrm{PM}_{2.5}$, air temperature and relative humidity were extracted 
from the location (latitude and longitude) of the cases and controls. Exposures between the monitoring stations were estimated using inverse distance weighted (IDW) interpolation of the BLANKeT network data, using the gstat packaging in $R 3.4$ [23]. Exposure values were calculated at lag times of $0-48 \mathrm{~h}$ prior to the EAD and the 24-h average on the same day (0-24 h prior) and at 1-day lag (24-48 h lag).

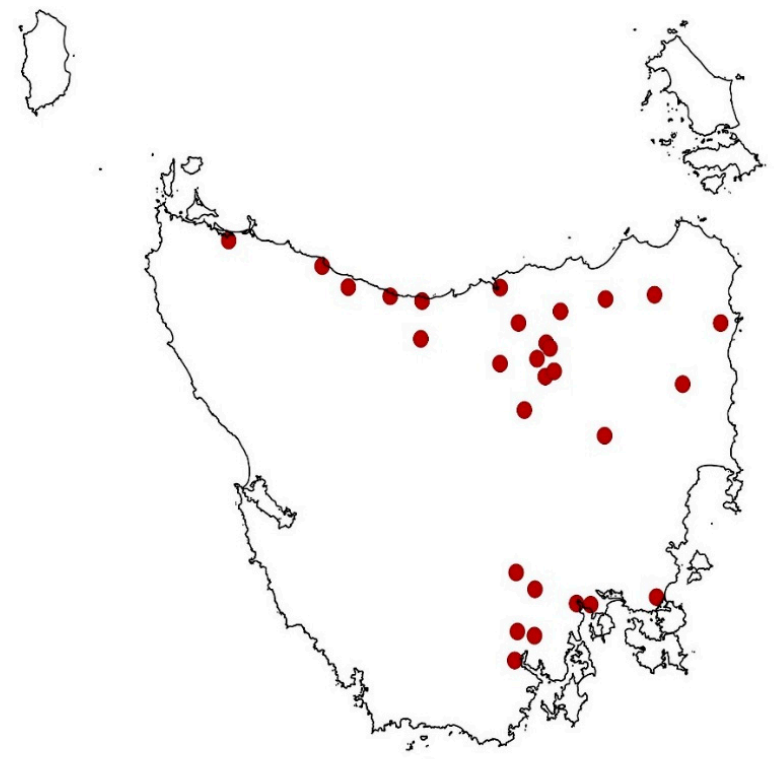

Figure 1. Location of the 21 Base Line Air Network of EPA Tasmania station. Most stations are located in the towns and cities in northern coastal, northeastern and southeastern Tasmania.

\subsection{Outcome Data}

The primary endpoint of interest was EAD. An EAD was defined as an ambulance dispatched within Tasmania during the study period with information recorded on the dispatch category. EAD data were received from the Tasmanian Ambulance Service Computer Aided Dispatch System (CAD), which uses trained operators to answer emergency calls and dispatch ambulances. CAD is based on the 37 Medical Priority Dispatch System (MPDS) categories. The MPDS categories, which were developed by the International Academies of Ambulance Dispatch, are used throughout Australia and in comparable countries, such as the United Kingdom and the United States [15,24]. The data that were available included the time of the call, location of the incident, age and sex of the case and the MPDS category. Data on inter-facility transfers or motor vehicle crash notifications were not received. Cases that were categorized as "Standby" or that did not have an MPDS category were excluded. All-causes, all non-trauma causes and the MPDS categories that have previously been associated with acute health effects from PM [15,20,25] were analyzed. The categories included: chest pain; heart problems (non-chest pain); stroke; cardiac or respiratory arrest or death; breathing problems; diabetic problems; and unconscious or fainting.

\subsection{Statistical Analysis}

Population data from the Australian Bureau of Statistics (June 2015) were used to calculate age-specific and regional rates of ambulance usage. Statistical analyses were performed using Stata version 14.2 (Statacorp). A conditional multivariate logistic regression was performed to calculate adjusted odds ratios for the association between an increase of $10 \mu \mathrm{g} / \mathrm{m}^{3}$ in $\mathrm{PM}_{2.5}$ and EAD at the time of the event and at 1-h lag periods from 1-47 $\mathrm{h}$ prior to the EAD and for the same day (mean of 0-24 $\mathrm{h}$ prior to EAD) and at a 1-day lag (mean of 24-48 h prior to EAD). Covariates were the preceding 24-h 
mean temperature and 24-h mean relative temperature. Odds ratios were considered to be significant if the $95 \%$ confidence interval did not cross 1 and $p$-values were $<0.05$.

\subsection{Ethics}

The study was approved by the Tasmanian Health and Medical Human Research Ethics Committee (Reference number H0012974) and the Australian National University Human Research Ethics Committee (Protocol 2016/603).

\section{Results}

Data were received on 14,512 EAD, of which 36 were excluded (those categorized as "Standby" or did not have an MPDS category). This resulted in a final total of 14,476 cases. The matching of cases to controls according to the day of the week within the month resulted in 48,984 controls. Males and females were equally represented (approximately $50 \%$ each). About half $(7513 ; 52 \%)$ were from Southern Tasmania, which corresponds to a similar proportion of the Tasmanian population $(262,500$; $51 \%)$ (Table 1).

The average daily frequency of EAD across the study period was 160. Age-specific EAD was highest among the 85 and older age group with an average of 144 EAD per 100,000 population per day during the 91-day study period. This was 16-fold higher than the lowest age group of 5-14 years, which had an average of 9 EAD per 100,000 population per day over the study period. The most common MPDS categories were sick person $(1925 ; 13 \%)$, chest pain (non-traumatic) $(1788 ; 12 \%)$ and falls $(1585 ; 11 \%)$ (Table 2).

Table 1. Demographic features, location and timing of the cases and the Tasmanian population.

\begin{tabular}{ccc}
\hline & Cases & Tasmania \\
\hline Total EAD & Number (\%) & Number (\%) \\
Median Age (Years) & $14,476(100)$ & NA \\
Sex & 57 & 42 \\
Female & $7216(49.8)$ & $255,728(49.4)$ \\
Male & $7174(49.6)$ & $261,860(50.6)$ \\
Unspecified & $86(0.6)$ & \\
Region & & \\
North & $3747(26.0)$ & $143,537(27.7)$ \\
Northwest & $3145(21.8)$ & $111,566(22.0)$ \\
South & $7513(52.1)$ & $262,485(50.7)$ \\
\hline
\end{tabular}

Table 2. Number and proportion of EAD by MPDS category in the period of 1 January to 31 March 2016.

\begin{tabular}{cc}
\hline MPDS Category & Number (\%) \\
\hline Sick person & $1925(13.3)$ \\
Chest pain (non-traumatic) & $1788(12.4)$ \\
Falls & $1585(10.9)$ \\
Breathing problems & $1292(8.9)$ \\
Unconscious/fainting & $961(6.6)$ \\
Abdominal pain/problems & $913(6.3)$ \\
Evaluation-interfacility & $743(5.1)$ \\
Traffic/transportation accidents & $579(4.0)$ \\
Traumatic injury & $485(3.4)$ \\
Convulsions/fitting & $446(3.1)$ \\
Hemorrhage/lacerations & $421(2.9)$ \\
Overdose/poisoning & $406(2.8)$ \\
Stroke & $365(2.5)$ \\
\hline
\end{tabular}


Table 2. Cont.

\begin{tabular}{cc}
\hline MPDS Category & Number (\%) \\
\hline Psychiatric/abnormal behavior or suicidal & $350(2.4)$ \\
Back pain & $333(2.3)$ \\
Heart problems (non-chest pain) & $325(2.2)$ \\
Allergies/envenomation & $323(2.2)$ \\
Headache & $236(1.6)$ \\
Unknown problem & $194(1.3)$ \\
Assault/sexual attack & $187(11.3)$ \\
Diabetic problems & $157(1.1)$ \\
Cardiac or respiratory arrest/death & $128(0.9)$ \\
Pregnancy/childbirth/miscarriage & $127(0.9)$ \\
Other * & $207(1.5)$ \\
Total & 14,476 \\
\hline
\end{tabular}

* Choking; burns/explosion; eye problems/injury; bite/attack; Stab/gunshot/penetrating trauma; electrocution/lightning; heat/cold exposure; carbon monoxide/inhalation/hazmat; drowning/diving/scuba accident; inaccessible incident/entrapment.

During the study period, BLANKeT stations in northern Tasmania recorded two distinct periods of $\mathrm{PM}_{2.5}$ that were higher than the NEPM standard (Figure 2). These periods corresponded with the landscape fires, of which most were in northern and northwestern Tasmania. Across the three major urban centers in Tasmania, the NEPM Standard was exceeded on two days in Hobart (southern Tasmania), six days in Launceston (northern Tasmania) and seven days in Devonport (northwestern Tasmania).

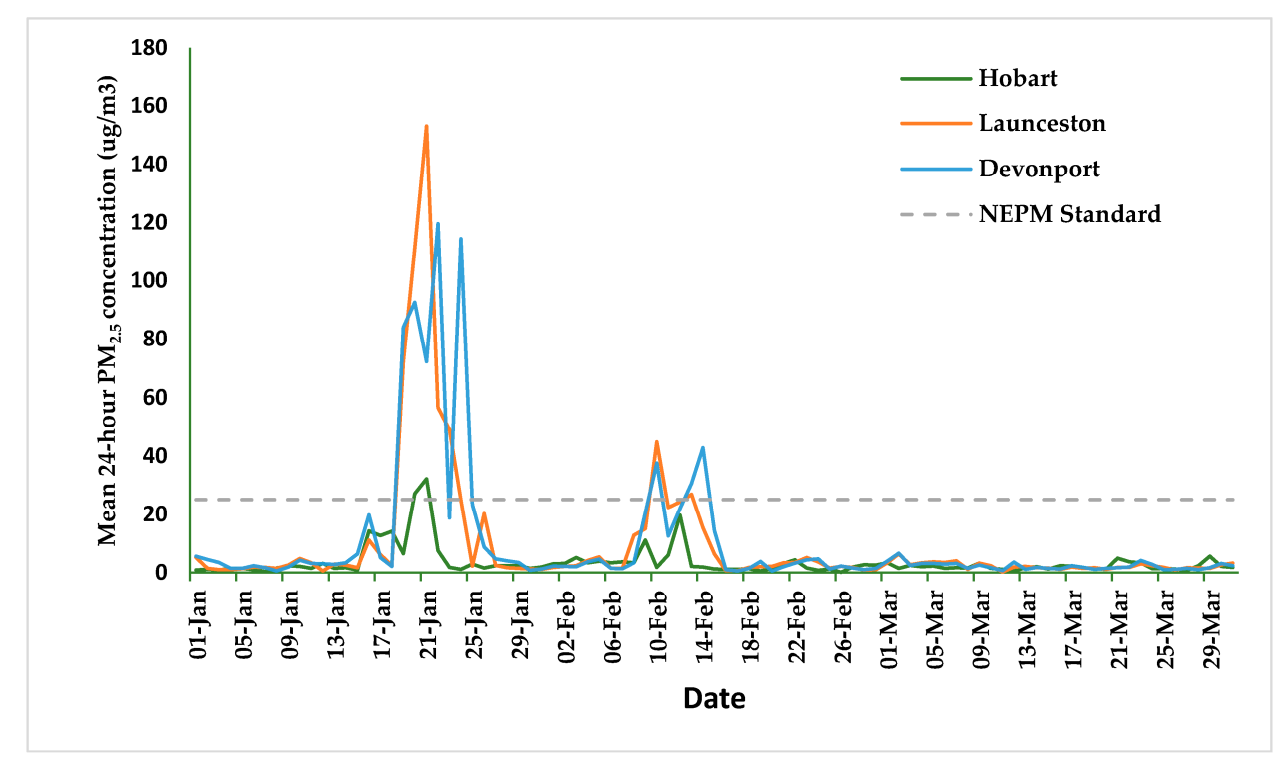

Figure 2. Mean 24-h $\mathrm{PM}_{2.5}$ concentration at Devonport (northwest Tasmania), Launceston (northern Tasmania), Hobart (southern Tasmania) and the NEPM 24-h standard in the period of 1 January to 31 March 2016.

In the multivariable analysis, there was no association between an increase of $10 \mu \mathrm{g} / \mathrm{m}^{3}$ in $\mathrm{PM}_{2.5}$ and all-cause EAD (same day OR 1.00, 95\% CI 0.90-1.01, $p=0.88$; 1-day lag OR 1.00, 95\% CI 0.99-1.02, $p=0.59$ ) (Table 3). In the analysis conducted according to selected MPDS dispatch categories, EAD for breathing problems were increased at lag times of 40 and $42 \mathrm{~h}$ (Figure 3) with a non-significant positive association at 1-day lag (OR 1.04, 95\% CI 1.00-1.08, $p=0.06$ ) (Table 3).

EAD for stroke were increased at lag times of 12-16, 19-22, 26-31 and $35 \mathrm{~h}$ (Figure 3) with significant positive associations on the same day (OR 1.10, 95\% CI 1.02-1.19, $p=0.01)$ ) and at 1-day lag 
times (OR 1.10, 95\% CI 1.02-1.18, $p=0.02$ ) (Table 3). Diabetic problems were increased at lag times of $26,36,38-40,45$ and $46 \mathrm{~h}$ (Figure 3 ) and there was a non-significant positive association at 1-day lag (OR 1.11, 95\% CI 0.99-1.22, $p=0.08$ ) (Table 3).

No associations were observed for an increase of $10 \mu \mathrm{g} / \mathrm{m}^{3}$ in $\mathrm{PM}_{2.5}$ and EAD for cardiac or respiratory arrest, unconscious/fainting, heart problems (non-chest pain) or non-trauma causes (Table 3).

Table 3. Adjusted odds ratio, 95\% confidence interval and $p$-value for an increase of $10 \mu \mathrm{g} / \mathrm{m}^{3}$ in $\mathrm{PM}_{2.5}$ for all causes and selected EAD dispatch categories at same day and 1-day lag.

\begin{tabular}{|c|c|c|c|c|c|c|c|}
\hline \multirow[t]{2}{*}{ Dispatch Category } & \multirow[t]{2}{*}{ Number (\%) } & \multicolumn{3}{|c|}{ Same Day Lag (0-24 h) } & \multicolumn{3}{|c|}{1 Day Lag (24-48 h) } \\
\hline & & Odds Ratio & $95 \% \mathrm{CI}$ & $p$-Value & Odds Ratio & $95 \% \mathrm{CI}$ & $p$-Value \\
\hline All causes & $14,476(100)$ & 1.00 & $0.99-1.01$ & 0.88 & 1.00 & $0.99-1.02$ & 0.59 \\
\hline Non-trauma causes & $9219(63.7)$ & 0.99 & $0.98-1.01$ & 0.37 & 1.00 & $0.98-1.01$ & 0.77 \\
\hline $\begin{array}{c}\text { Chest pain } \\
\text { (non-traumatic) }\end{array}$ & $1788(12.4)$ & 0.98 & $0.95-1.02$ & 0.34 & 0.99 & $0.95-1.03$ & 0.49 \\
\hline Breathing problems & $1292(8.9)$ & 1.02 & $0.98-1.05$ & 0.36 & 1.04 & $01.00-1.08$ & 0.06 \\
\hline Unconscious/fainting & $961(6.6)$ & 0.99 & $0.95-1.03$ & 0.59 & 0.99 & $0.95-1.04$ & 0.70 \\
\hline Stroke & $364(2.5)$ & 1.10 & $1.02-1.19$ & 0.01 & 1.10 & $1.02-1.18$ & 0.02 \\
\hline $\begin{array}{l}\text { Heart problems } \\
\text { (non-chest pain) }\end{array}$ & $325(2.2)$ & 0.99 & $0.91-1.08$ & 0.84 & 0.95 & $0.86-1.06$ & 0.37 \\
\hline Diabetic problems & $157(1.1)$ & 1.07 & $0.96-1.18$ & 0.21 & 1.10 & $0.99-1.22$ & 0.08 \\
\hline $\begin{array}{c}\text { Cardiac or respiratory } \\
\text { arrest/death }\end{array}$ & $128(0.9)$ & 0.98 & $0.83-1.14$ & 0.76 & 1.00 & $0.88-1.13$ & 0.98 \\
\hline
\end{tabular}

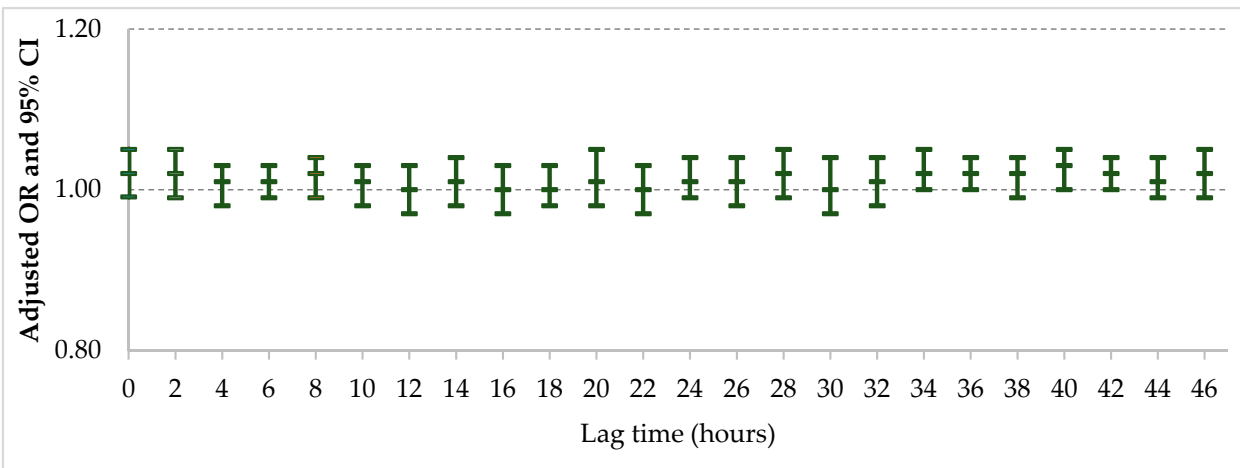

(a)

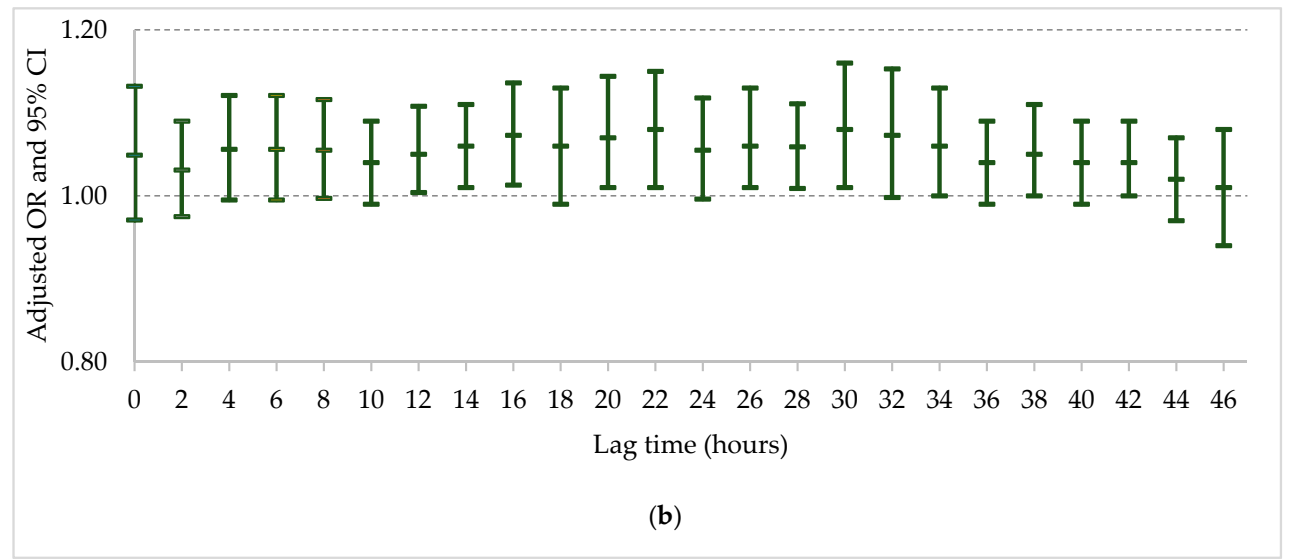

Figure 3. Cont. 


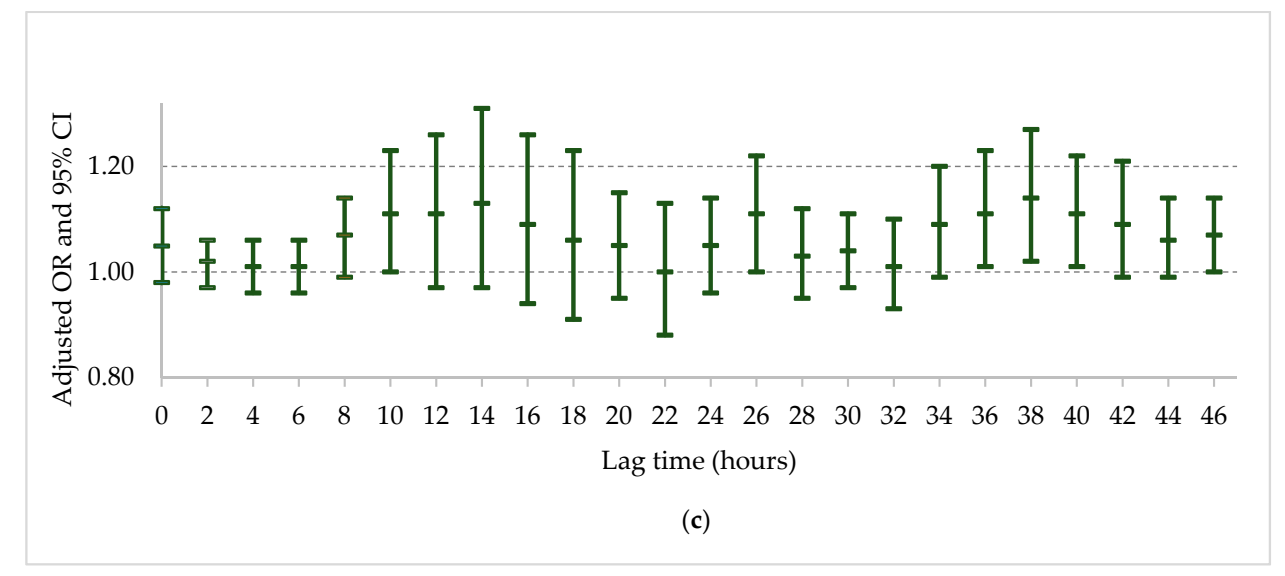

Figure 3. Adjusted odds ratios and $95 \%$ confidence intervals for an increase of $10 \mu \mathrm{g} / \mathrm{m}^{3}$ in $\mathrm{PM}_{2.5}$ and EAD for (a) breathing problems, (b) stroke and (c) diabetic problems with $0-46 \mathrm{~h}$ lag periods.

\section{Discussion}

In this study, the elevations in $\mathrm{PM}_{2.5}$ concentration were associated with significant increases in EAD for the dispatch categories of breathing problems, diabetes and stroke at hourly lag times of $12-46 \mathrm{~h}$. In the analysis over 24-h time periods, an increase of $10 \mu \mathrm{g} / \mathrm{m}^{3}$ in $\mathrm{PM}_{2.5}$ was associated with a significant increase in EAD for stroke on the same day and at 1-day lag. There were positive associations between an increase of $10 \mu \mathrm{g} / \mathrm{m}^{3}$ in $\mathrm{PM}_{2.5}$ and the dispatch categories of diabetic problems and breathing problems at 1-day lag although these associations did not reach statistical significance.

The lag time between the exposure to elevated concentrations of $\mathrm{PM}_{2.5}$ and the acute health event is consistent with findings in other studies as the health effects of landscape fire smoke are usually delayed by hours up to several days. The physiological mechanisms for the lag time is not completely understood but has been shown to occur as a consequence of the direct irritant and pro-inflammatory effects of PM. These effects trigger metabolic processes, involving cytokine release, oxidative stress, thrombosis and coagulation, which take time to have actual health consequences [26-29].

The finding of increased concentrations of $\mathrm{PM}_{2.5}$ not being associated with the dispatch category of chest pain is consistent with some, but not all, other studies $[15,18]$. This may be because the dispatch category of chest pain is not specific and has been shown to have a wide range of causes, including cardiovascular, gastrointestinal and psychological problems [15]. Only a certain proportion of these are likely to be affected by $\mathrm{PM}_{2.5}$ exposure. The finding of increased $\mathrm{PM}_{2.5}$ concentration not being associated with cardiac arrest contrasts with the results of several other studies [12-14,26,30]. However, the confidence intervals for this category were wide and therefore, the results should be interpreted with caution.

At a population level, an odds ratio of 1.1 for the dispatch category of stroke at 1-day lag corresponds to an increase of $10 \%$ in EAD for stroke for every $10 \mu \mathrm{g} / \mathrm{m}^{3}$ increase in $\mathrm{PM}_{2.5}$. This would equate to a $100 \%$ increase —or doubling—of stroke-related EAD following an increase of $100 \mu \mathrm{g} / \mathrm{m}^{3}$ in $\mathrm{PM}_{2.5}$. During the study period, 24-h average $\mathrm{PM}_{2.5}$ concentrations of up to $300 \mu \mathrm{g} / \mathrm{m}^{3}$ were recorded (highest single reading of $2000 \mu \mathrm{g} / \mathrm{m}^{3}$ ) by the BLANKeT network air monitoring stations, which were 30-fold higher than an increase of $10 \mu \mathrm{g} / \mathrm{m}^{3}$ in $\mathrm{PM}_{2.5}$. These findings could have an impact on ambulance services in Tasmania during severe smoke events. Notwithstanding, the daily average number of EAD for stroke in Tasmania is small and an increase in all-cause EAD was not found, which may have been expected. This suggests that other factors may also contribute. In comparison, a study investigating the impact of smoke-related $\mathrm{PM}_{2.5}$ on all-cause mortality and hospitalizations for cardiovascular and respiratory conditions in Sydney (population of approximately 5 million, which is 10-fold greater than Tasmania) estimated that there were 29 cardiovascular hospitalizations, 
58 respiratory hospitalizations and 14 deaths due to hazard reduction burns during a single month in 2016 [31].

A major strength of this study was that the $\mathrm{PM}_{2.5}$ concentration was matched geospatially with acute health events as measured by EAD. This information is not available in other settings, such as emergency departments or hospitals, and it provides a more precise estimate of the association between exposure to $\mathrm{PM}_{2.5}$ and EAD. Another strength of this study was the time-stratified case crossover design where cases act as their own controls, thus removing confounding factors, such as age, sex and comorbidities.

A limitation of the study was that it was undertaken over a relatively short time-frame compared with other environmental epidemiological studies, which resulted in small sample sizes within MPDS categories. Another limitation is that MPDS clinical categories are designed to facilitate rapid ambulance dispatch and do not consistently correspond with a final diagnosis that corresponds with the International Classification of Diseases coding system [15]. Therefore, it cannot be concluded that an increase in the dispatch category of stroke, diabetic problems or breathing problems represents a definite increase in these conditions.

This study did not distinguish between the sources of $\mathrm{PM}_{2.5}$ or other air pollutants but it is unlikely that sources other than fire smoke significantly contributed to exposures because of the low population density and limited number of industrial and traffic sources of air pollution in Tasmania. The Tasmanian Environmental Protection Agency report that ambient levels of industrial and vehicle generated pollutants (ozone, nitrogen dioxide, carbon monoxide and sulfur dioxide) are very low, while smoke from landscape fires and domestic wood heaters is the major contributor to air pollution in Tasmania [21]. Screening for these pollutants does take place and concentrations are consistently found to be well below national standards. Fire smoke is a mixture of hundreds of different aerosols and gases. In the context of open burning, PM can be considered as a marker of this mixture and it is recognized as the primary driver of adverse health impacts from fire smoke $[1,8]$.

Finally, a type 1 statistical error may have occurred in the logistic regression at hourly lag times across multiple ambulance dispatch categories. To reduce the type 1 error, the results of each dispatch category analysis were interpreted at hourly lag times in the context of the same day and 1-day lag periods, which has been done in previous studies.

Landscape wildfires, which are the greatest natural disaster risk posed to Tasmania, are expected to increase in frequency and severity due to global warming [32,33]. In addition to the ecological and economic impact of landscape fires, the contribution of landscape fire smoke to the global burden of disease via acute cardiovascular and respiratory events is increasingly being recognized. Preparing for landscape fire events and promoting methods to reduce the harms of smoke exposure, such as through the use of air filters, are important areas for public health officials to focus on into the future.

\section{Conclusions}

In this study, an increase of $10 \mu \mathrm{g} / \mathrm{m}^{3}$ in $\mathrm{PM}_{2.5}$ was positively associated with an increase in EAD for the dispatch categories of stroke, breathing problems and diabetic problems at lag times of 12-47 h. There was also an increase in stroke on the same day and at 1-day lag and non-significant associations between breathing problems and diabetic problems at 1-day lag. There was no increase in all-cause EAD. This study indicates that increased concentrations of $\mathrm{PM}_{2.5}$ are associated with an increased demand for selected ambulance dispatch categories. However, the absolute increase is small and may not have an impact on ambulance services unless the $\mathrm{PM}_{2.5}$ concentration increase is very high and is sustained for several days within or adjacent to a large population, such as in a capital city in mainland Australia.

These findings, which were obtained from a relatively small and dispersed population during a period of multiple landscape fires, add to the expanding literature on the acute health effects of exposure to landscape firesmoke. In particular, we found that increased concentrations of $\mathrm{PM}_{2.5}$ from fire smoke are associated with a range of acute health effects and have a significant impact on public 
health at a population level. These findings will be used for ambulance service planning and by public health professionals in developing communication plans to prepare for and respond to landscape fires into the future.

Author Contributions: Conceptualization, L.E. and F.J.; Methodology, L.E., F.J. and F.S.; Validation, F.J. and F.S.; Formal Analysis, L.E.; Investigation, L.E.; Resources, G.W. and F.J.; Data Curation, G.W. and L.E.; Writing-Original Draft Preparation, L.E.; Writing-Review \& Editing, S.W., M.V. and F.J.; Visualization, L.E.; Supervision, F.J., S.W. and M.V.; Project Administration, F.J.

Funding: This research received no external funding.

Acknowledgments: Laura Edwards is a Master of Philosophy in Applied Epidemiology (MAE) Scholar at the National Centre for Epidemiology and Population Health, Australian National University and a Public Health Medicine Registrar at the Department of Health and Human Services, Tasmania. Her position at the Department of Health was funded by the Australian Department of Health Specialist Training Program. The authors would like to acknowledge the contributions of Petr Otahal at Menzies Institute for Health Research for providing statistical advice on the study and John Innis at the Environmental Protection Agency providing feedback on the study findings and report.

Conflicts of Interest: The authors declare no conflict of interest.

\section{References}

1. Reid, C.E.; Brauer, M.; Johnston, F.H.; Jerrett, M.; Balmes, J.R.; Elliott, C.T. Critical Review of Health Impacts of Wildfire Smoke Exposure. Environ. Health Perspect. 2016, 124, 1334-1343. [CrossRef] [PubMed]

2. Cohen, A.J.; Brauer, M.; Burnett, R.; Anderson, H.R.; Frostad, J.; Estep, K.; Balakrishnan, K.; Brunekreef, B.; Dandona, L.; Dandona, R.; et al. Estimates and 25-year trends of the global burden of disease attributable to ambient air pollution: An analysis of data from the Global Burden of Diseases Study 2015. Lancet 2017, 389, 1907-1918. [CrossRef]

3. Johnston, F.H.; Henderson, S.B.; Chen, Y.; Randerson, J.T.; Marlier, M.; Defries, R.S.; Kinney, P.; Bowman, D.M.; Brauer, M. Estimated global mortality attributable to smoke from landscape fires. Environ. Health Perspect. 2012, 120, 695-701. [CrossRef] [PubMed]

4. Adetona, O.; Reinhardt, T.E.; Domitrovich, J.; Broyles, G.; Adetona, A.M.; Kleinman, M.T.; Ottmar, R.D.; Naeher, L.P. Review of the health effects of wildland fire smoke on wildland firefighters and the public. Inhal. Toxicol. 2016, 28, 95-139. [CrossRef] [PubMed]

5. Haikerwal, A.; Reisen, F.; Sim, M.R.; Abramson, M.J.; Meyer, C.P.; Johnston, F.H.; Dennekamp, M. Impact of smoke from prescribed burning: Is it a public health concern? J. Air Waste Manag. Assoc. 2015, 65, 592-598. [CrossRef] [PubMed]

6. Haikerwal, A.; Akram, M.; Del Monaco, A.; Smith, K.; Sim, M.R.; Meyer, M.; Tonkin, A.M.; Abramson, M.J.; Dennekamp, M. Impact of Fine Particulate Matter $\left(\mathrm{PM}_{2.5}\right)$ Exposure During Wildfires on Cardiovascular Health Outcomes. J. Am. Heart Assoc. 2015, 4, e001653. [CrossRef] [PubMed]

7. Johnston, F.H.; Purdie, S.; Jalaludin, B.; Martin, K.L.; Henderson, S.B.; Morgan, G.G. Air pollution events from forest fires and emergency department attendances in Sydney, Australia 1996-2007: A case-crossover analysis. Environ. Health 2014, 13, 105. [CrossRef] [PubMed]

8. Cascio, W.E. Wildland fire smoke and human health. Sci. Total Environ. 2017, 624, 586-595. [CrossRef] [PubMed]

9. Johnston, F.H. Understanding and managing the health impacts of poor air quality from landscape fires. Med. J. Aust. 2017, 207, 229-230. [CrossRef] [PubMed]

10. Broome, R.A.; Fann, N.; Cristina, T.J.; Fulcher, C.; Duc, H.; Morgan, G.G. The health benefits of reducing air pollution in Sydney, Australia. Environ. Res. 2015, 143, 19-25. [CrossRef] [PubMed]

11. GBD Compare: Deaths Attributable to Ambient Particulate Matter Pollution. Available online: https: / /vizhub.healthdata.org/gbd-compare/ (accessed on 15 April 2018).

12. Straney, L.; Finn, J.; Dennekamp, M.; Bremner, A.; Tonkin, A.; Jacobs, I. Evaluating the impact of air pollution on the incidence of out-of-hospital cardiac arrest in the Perth Metropolitan Region: 2000-2010. J. Epidemiol. Community Health 2014, 68, 6-12. [CrossRef] [PubMed]

13. Dennekamp, M.; Akram, M.; Abramson, M.J.; Tonkin, A.; Sim, M.R.; Fridman, M.; Erbas, B. Outdoor air pollution as a trigger for out-of-hospital cardiac arrests. Epidemiology 2010, 21, 494-500. [CrossRef] [PubMed] 
14. Dennekamp, M.; Straney, L.D.; Erbas, B.; Abramson, M.J.; Keywood, M.; Smith, K.; Sim, M.R.; Glass, D.C.; Del Monaco, A.; Haikerwal, A.; et al. Forest Fire Smoke Exposures and Out-of-Hospital Cardiac Arrests in Melbourne, Australia: A Case-Crossover Study. Environ. Health Perspect. 2015, 123, 959-964. [CrossRef] [PubMed]

15. Salimi, F.; Henderson, S.B.; Morgan, G.G.; Jalaludin, B.; Johnston, F.H. Ambient particulate matter, landscape fire smoke, and emergency ambulance dispatches in Sydney, Australia. Environ. Int. 2017, 99, $208-212$. [CrossRef] [PubMed]

16. Michikawa, T.; Ueda, K.; Takeuchi, A.; Kinoshita, M.; Hayashi, H.; Ichinose, T.; Nitta, H. Impact of short-term exposure to fine particulate matter on emergency ambulance dispatches in Japan. J. Epidemiol. Community Health 2015, 69, 86-91. [CrossRef] [PubMed]

17. Phung, V.L.H.; Ueda, K.; Kasaoka, S.; Seposo, X.; Tasmin, S.; Yonemochi, S.; Phosri, A.; Honda, A.; Takano, H.; Michikawa, T.; et al. Acute Effects of Ambient $\mathrm{PM}_{2.5}$ on All-Cause and Cause-Specific Emergency Ambulance Dispatches in Japan. Int. J. Environ. Res. Public Health 2018, 15, 307. [CrossRef] [PubMed]

18. Youngquist, S.T.; Hood, C.H.; Hales, N.M.; Barton, C.C.; Madsen, T.E.; Arden Pope, C. Association between EMS calls and fine particulate air pollution in Utah. Air Qual. Atmos. Health 2016, 9, 887-897. [CrossRef]

19. Liu, R.; Zeng, J.; Jiang, X.; Chen, J.; Gao, X.; Zhang, L.; Li, T. The relationship between airborne fine particle matter and emergency ambulance dispatches in a southwestern city in Chengdu, China. Environ. Pollut. 2017, 229, 661-667. [CrossRef] [PubMed]

20. Zauli Sajani, S.; Alessandrini, E.; Marchesi, S.; Lauriola, P. Are day-to-day variations of airborne particles associated with emergency ambulance dispatches? Int. J. Occup. Environ. Health 2014, 20, 71-76. [CrossRef] [PubMed]

21. Environment Protection Authority. Tasmanian Air Monitoring Report 2013; Environment Protection Authority: Hobart, Australia, 2014.

22. Jaakkola, J.J. Case-crossover design in air pollution epidemiology. Eur. Respir. J. Suppl. 2003, 40, 81s-85s. [CrossRef] [PubMed]

23. Graler, B.; Pemesma, E.; Heuvelink, G. Spatio-temporal interpolation using gstat. R. J. 2016, 8, $204-218$.

24. Clawson, J.; Olola, C.; Heward, A.; Patterson, B.; Scott, G. Profile of emergency medical dispatch calls for breathing problems within the medical priority dispatch system protocol. Prehosp. Disaster Med. 2008, 23, 412-419. [CrossRef] [PubMed]

25. Atkinson, R.W.; Kang, S.; Anderson, H.R.; Mills, I.C.; Walton, H.A. Epidemiological time series studies of $\mathrm{PM}_{2.5}$ and daily mortality and hospital admissions: A systematic review and meta-analysis. Thorax 2014, 69, 660-665. [CrossRef] [PubMed]

26. Cesaroni, G.; Forastiere, F.; Stafoggia, M.; Andersen, Z.J.; Badaloni, C.; Beelen, R.; Caracciolo, B.; de Faire, U.; Erbel, R.; Eriksen, K.T.; et al. Long term exposure to ambient air pollution and incidence of acute coronary events: Prospective cohort study and meta-analysis in 11 European cohorts from the ESCAPE Project. BMJ 2014, 348, f7412. [CrossRef] [PubMed]

27. Guarnieri, M.; Balmes, J.R. Outdoor air pollution and asthma. Lancet 2014, 383, 1581-1592. [CrossRef]

28. Shao, J.; Wheeler, A.J.; Chen, L.; Strandberg, B.; Hinwood, A.; Johnston, F.H.; Zosky, G.R. The proinflammatory effects of particulate matter on epithelial cells are associated with elemental composition. Chemosphere 2018, 202, 530-537. [CrossRef] [PubMed]

29. Simkhovich, B.Z.; Kleinman, M.T.; Kloner, R.A. Air Pollution and Cardiovascular Injury: Epidemiology, Toxicology, and Mechanisms. J. Am. Coll. Cardiol. 2008, 52, 719-726. [CrossRef] [PubMed]

30. Pradeau, C.; Rondeau, V.; Leveque, E.; Guernion, P.Y.; Tentillier, E.; Thicoipe, M.; Brochard, P. Air pollution and activation of mobile medical team for out-of-hospital cardiac arrest. Am. J. Emerg. Med. 2015, 33, 367-372. [CrossRef] [PubMed]

31. Broome, R.A.; Johnston, F.H.; Horsley, J.; Morgan, G.G. A rapid assessment of the impact of hazard reduction burning around Sydney, May 2016. Med. J. Aust. 2016, 205, 407-408. [CrossRef] [PubMed] 
32. Environment and Communications References Committee. Responses to, and Lessons Learnt from, the January and February 2016 Bushfires in Remote Tasmanian Wilderness; The Senate: Canberra, Australia, 2016.

33. White, C.; Remenyi, T.; McEvoy, D.; Trundle, A.; Corney, S. Tasmania State Natural Disaster Risk Assessment; University of Tasmania: Hobart, Australia, 2016.

(c)

(C) 2018 by the authors. Licensee MDPI, Basel, Switzerland. This article is an open access article distributed under the terms and conditions of the Creative Commons Attribution (CC BY) license (http:/ / creativecommons.org/licenses/by/4.0/). 